\title{
The Web Portal: Collecting and Presenting the Addresses of Different Things on the Web
}

\author{
Avinash Nalawade ${ }^{1}$, Rohit Sawant ${ }^{2}$ \\ Student, Computer Science \& Engg, DACOE, Karad, India ${ }^{1,2}$
}

\begin{abstract}
While the Web has evolved to be a global information platform for anyone to use, this web portal is also using the Web to their own advantages. This web portal work within the entire city. Different things included from this city may be ATM's, Banks, Hospitals, Schools, Colleges, Hotels, Shops, etc. This web portal will be helpful for citizens to detect the information of particular thing as they require. The owners first register their information with address on the web portal with their unique login ID and password for authentication. Owners can also notifies their daily notifications and also advertise their products on the web portal for increase the business growth. Citizen having no need of any authentication on the web portal. They can just enters into the portal and search their category and find out the nearest address from different available options. A web portal software module executing on a computer system for locating relevant Web pages includes instructions to collect information regarding a user from the web portal. Instructions are provided to register a business profile based on the information collected. Instructions are also provided to receive a search entry from portal. The instant portal software module generates a plurality of queries based on the search entry to search for relevant Web page of addresses.
\end{abstract}

Keywords: Web portal, Webpages, Addresses.

\section{INTRODUCTION}

In "Web portal project" an owner can use his her Manage privileges online without any difficulty. HelShe has to fill a registration form to register himselflherself with their business. If all the entries are correct then a User Id and Password is given to the owner, by using that User ID and Password helshe can use his her rights. If conditions are wrong then that entry will be discarded efforts reduces. Portal is a term, generally synonymous with gateway, for a World Wide Web site that is or proposes to be a major starting site for users when they get connected to the Web or that users tend to visit as an anchor site. There are general portals and specialized or niche portals.

Some major general portals include Yahoo, Excite, Netscape, Lycos, CNET, Microsoft Network, and America Online'sAOL.com. Examples of niche portals include Garden.com (for gardeners), Fool.com (for investors), and SearchNetworking.com (for network administrators).A number of large access providers offer portals to the Web for their own users. Most portals have adopted the Yahoo style of content categories with a text-intensive, faster loading page that visitors will find easy to use and to return to. Companies with portal sites have attracted much stock market investor interest because portals are viewed as able to command large audiences and numbers of advertising viewers. Typical services offered by portal sites include a directory of Web sites, a facility to search for other sites, news, weather information, e-mail, stock quotes, phone and map information, and sometimes a community forum. Excite is among the first portals to offer users the ability to create a site that is personalized for individual interests. The term portal space is used to mean the total number of major sites competing to be one of the portals.

\section{LITERATURE SURVEY}

The Internet has become a major resource in modern business, thus electronic shopping has gained significance not only from the entrepreneur's but also from the customer's point of view. For the entrepreneur, electronic shopping generates new business opportunities and for the customer, it makes comparative shopping possible. As per a survey, most consumers of online stores are impulsive and usually make a decision to stay on a site within the first few seconds. "Website design is like a shop interior. If the shop looks poor or like hundreds of other shops the customer is most likely to skip to the other site [1].

This paper has given an overview of the developing Semantic Web infrastructure, showed how this relates to typical hypermedia research topics and given comprehensive pointers to the relevant literature. [2]

The portal ATMOS reflects current tendency of Environmental Sciences transformation into exact (quantitative) sciences and is quite effective example of modern Information Technologies and Environmental Sciences integration. It makes the portal both an auxiliary instrument to support interdisciplinary projects on Siberia regional environment and extensive educational resource providing an access to number of textbooks and monographs in the targeted domains of atmospheric sciences and their applications. It should be added that 


\section{IARJSET}

International Advanced Research Journal in Science, Engineering and Technology

National Conference on Innovative Applications and Research in Computer Science and Engineering (NCIARCSE-2017) AGTI's Dr. Daulatrao Aher College Engineering, Vidyanagar Extension, Karad

Vol. 4, Special Issue 4, January 2017

middleware developed to construct and support the portal sites allows one to design a management system for such projects as a part of relevant information computational site. In virtue of limited resources, currently it can be achieved on project to project basis only. [3]

\section{DESIGN AND PROPOSED WORK}

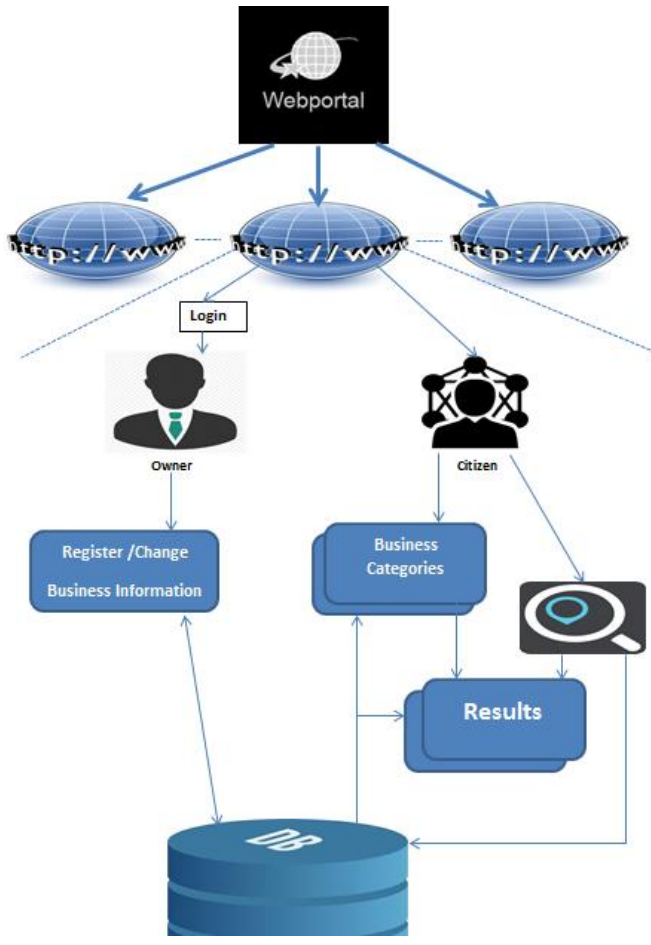

Fig : System Architecture

There are several users entered in this system. Functionalities of these are:

\section{A) Owner:}

Owner having functionalities are:

- Register Business Details.

- Register New Notifications

- Edit All Business Information

- Edit Own User Information

- Edit Access Secured Settings

- Monitor The Business Status

\section{B) Citizen:}

Citizen having functionalities are:

- Enters into the system without any authentication

- Search for particular thing with their category

- Detect the nearest address

\section{WEB TECHNOLOGY}

The users of this portal are belongs from different locations and can access this system on any electronic devices like laptop PCs Tablets etc. for this purpose we implement this system in web technology

\section{RESULTS OF ONE EXAMPLE}

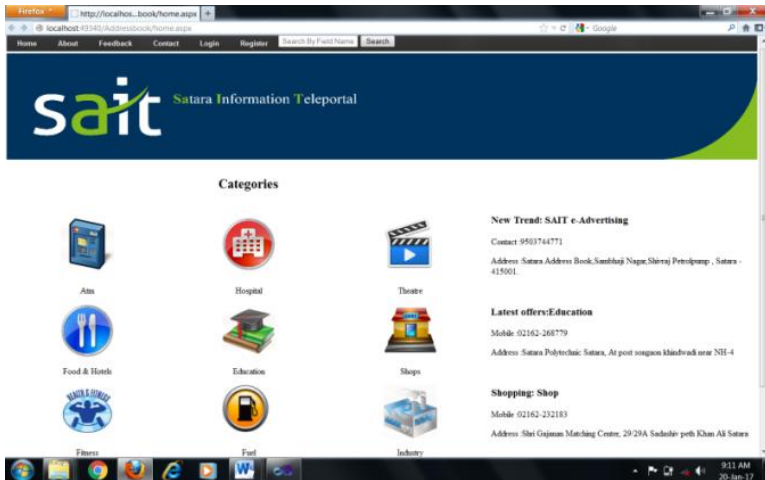

Fig 1: Home Page
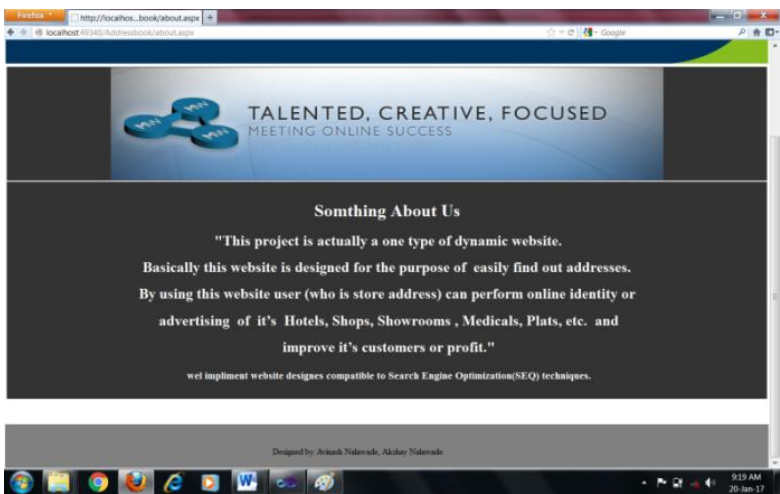

Fig 2: About
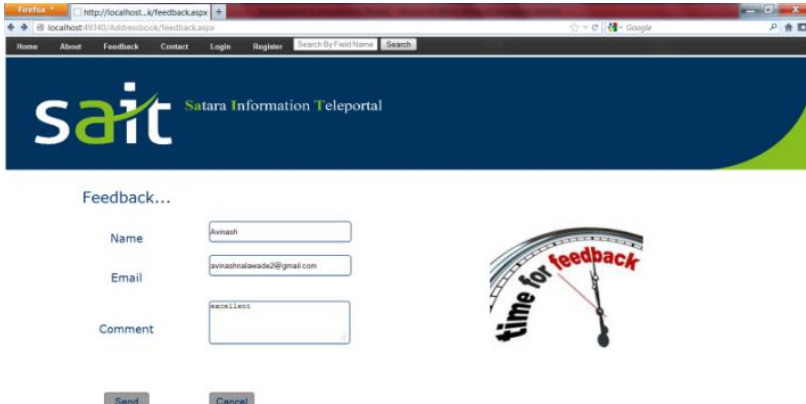

Send cancent

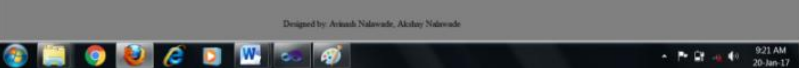

Fig 3: Feedback
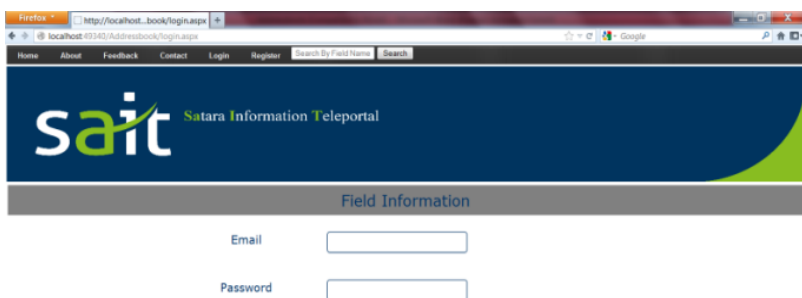

Sumit Bover

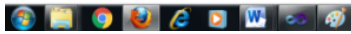

Fig 4: Login 
IARJSET

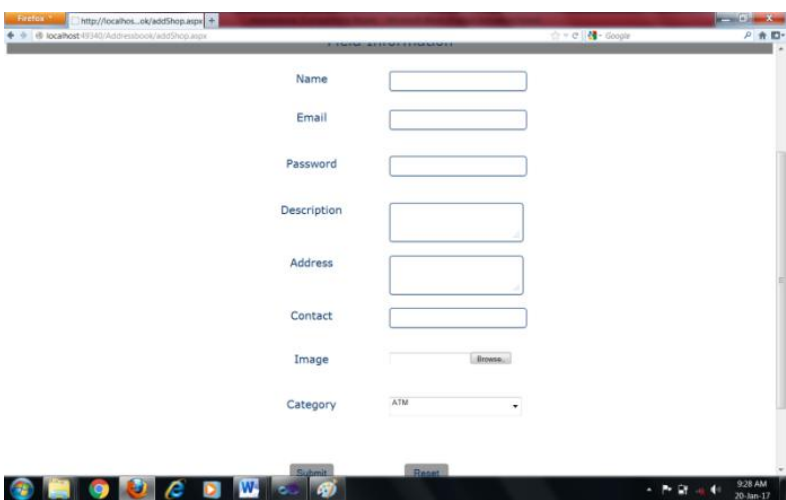

Fig 5: Register Business

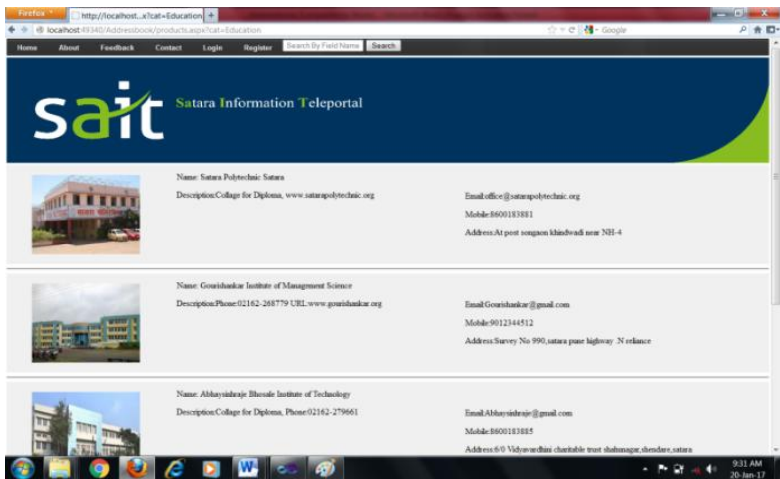

Fig 6: Education Category
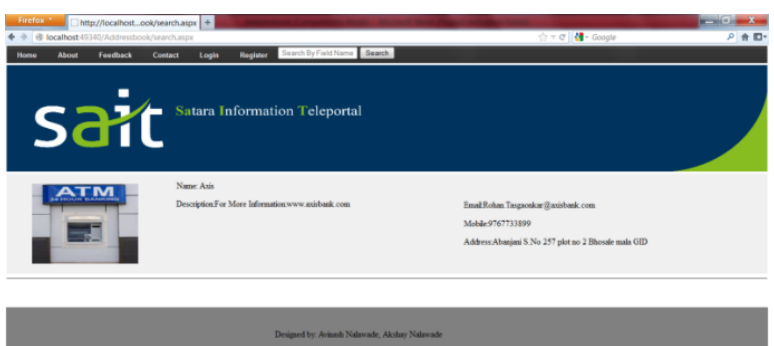

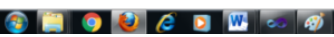

\section{Fig 7: Search Axis ATM}

\section{CONCLUSION}

This "Web portal project" is a smart way for citizens to easily and quickly detect information about particular things (like ATM's, Banks, Hospitals, Schools, Colleges, Hotels, Shops, etc.). Also useful for advertising the business and increase the business growth.

\section{REFERENCES}

1) Dr. HosseinHakimzadeh, Advisor Dr. Dana Vrajitoru Dr. Morteza Shafii Mousavi "THE DESIGN AND IMPLEMENTATION OF AN E-COMMERCE SITE FOR ONLINE BOOK SALES" May2007

2) Berners-Lee, James Hendler and OraLassila "The Semantic Web" May 17, 2001

3) E. P. Gordov, V. N. Lykosov, and A. Z. Fazliev "Web portal on environmental sciences "ATMOS" 2006 